\title{
Chapter 11 \\ Basic Psychological Needs, Procrastination and Coping in the Context of Healthy Aging
}

\author{
Janaina Pereira and Bárbara Gonzalez
}

\begin{abstract}
This study investigated the relations between basic psychological needs, coping strategies, procrastination, anxiety, depression, and stress, in the scope of self-determination theory (SDT) and healthy aging. A sample of university adult students $(N=221)$ aged $18-69$ years old, filled a set of questionnaires assessing these variables. The results showed that total basic psychological needs satisfaction has a positive relation with proactive coping, strategic planning, preventive coping, and instrumental support seeking, and a negative relation with procrastination, avoidance coping and anxiety, depression and stress. Proactive coping and strategic planning partially mediates the relationship between basic psychological needs total and procrastination. As age increased, there was more competence satisfaction, more adaptive coping strategies, and less procrastination, and anxiety, depression and stress. The results also emphasize the role of basic psychological needs as an important construct that may contribute to lower academic procrastination levels, through an increase of adaptive coping strategies. These results are discussed in the context of healthy aging, and how the academic context may increase the basic psychological needs satisfaction.
\end{abstract}

\subsection{Introduction}

Self-determination theory (SDT) is a macro theory of human motivation, personality and optimal functioning, and the satisfaction of inherent basic psychological needs is a core aspect in this conceptual framework (Deci \& Ryan, 2002). Healthy aging is an increasingly pertinent topic in societies, and it is meaningful to approach it within the scope of self-determination. This chapter focuses on a research to assess the relation among basic psychological needs satisfaction, procrastination, and coping strategies

\author{
J. Pereira $(\bowtie) \cdot$ B. Gonzalez \\ School of Psychology and Life Sciences of Lusophone University of Humanities and \\ Technologies (L.U.H.T.), Lisbon, Portugal \\ e-mail: js901901@gmail.com \\ B. Gonzalez \\ HEI-Lab: Digital Human-Environment Interactions Lab of L.U.H.T., Lisbon, Portugal
}


in the university context, with adult students of a broad age range. The chapter begins with the theoretical framework and literature review of several topics: SDT, basic psychological needs satisfaction, healthy aging, procrastination, and coping strategies. Then, we describe the methodological aspects of this research, and the results are discussed within this theoretical framework.

\subsection{Self-determination Theory}

The self-determination theory (SDT; Deci \& Ryan, 2000) is a widely studied theory of human motivation that provides a framework for understanding human tendency toward active engagement and development. SDT emphasizes that all humans have innate tendencies to engage in interesting activities, and to continuously refine their inner representation of themselves and their world (Deci \& Ryan, 1991).

SDT argues that the healthy organismic functioning, higher-quality behavior, mental health and psychological well-being are derived from the satisfaction of basic psychological needs (Deci \& Ryan, 2000). SDT assumes that the desire to reach the innate needs of each individual is fundamental for human behavior during the entire lifespan.

\subsubsection{Basic Psychological Needs}

Every person has an innate integrative tendency, which is in large part a function of the degree to which the basic psychological needs are fulfilled (Deci \& Ryan, 2000). These psychological needs, competence, relatedness and autonomy, are essential for ongoing psychological growth, integrity, and well-being (Deci \& Ryan, 2000). The fulfillment of these needs is essential to support volitional motivation and performance (Deci \& Ryan, 2000) and effective coping strategies (Ntoumanis, Edmunds, \& Duda, 2009). If the environment does not support and nurture them, it contributes to negative consequences, as pathology and ill-being (Ryan \& Deci, 2000). In the context of SDT, the satisfaction of the basic psychological needs is something that is built into our system, which is part of our evolved nature and therefore, it is natural rather than acquired (Deci \& Ryan, 2000).

The need for competence involves understanding how to attain various external and internal outcomes, and being efficacious in performing the requested action; autonomy refers to being self-initiating and self-regulating of one's own action; relatedness involves developing secure and satisfying connections with others in one's social environment (Deci, Vallerand, Pelletier, \& Ryan, 2011).

These needs are important because they provide criteria for specifying what are essential to life. At the same time, the concept of needs has an organismic nature, because it is reasonable to argue that organisms are "built for" the satisfaction of 
needs, that is, they have evolved into functional structures that can lead to sustenance and integrity (Deci \& Ryan, 2000).

\subsection{Healthy Aging}

According to Dziechciaz and Filip (2014), the aging of humans is a physiological and dynamic process ongoing with time. The process of human aging is complex and individualized, which occurs in the biological, psychological and social spheres. Traditionally, research have focused on negative aspects that may occur in latter stages of life, such as adverse changes in cognitive functions and a higher probability of depression.

Aging as the process of getting older begins very early and takes place throughout the life cycle (Fernandez-Ballesteros, 2013). Fernandez-Ballesteros (2013) stated the great variability in the ways of getting older, as they are a product of the interactions between personal features and the socio-cultural contexts in which people live.

The World Health Organization (2015) defined healthy aging as a process to optimize health and social participation to improve the quality of life as people grow older, as well as a process to maintain and develop the functional capabilities that contribute to the well-being of the elderly people.

Within the SDT approach, it is increasingly important to understand the factors that contribute to an active aging and well-being in the adult life span (Ryan \& Deci, 2000), and there is evidence for the critical role of competence, autonomy and relatedness in fostering well-being at all ages, suggesting that basic psychological needs influence well-being across life (Ryan \& La Guardia, 2000).

\subsection{Procrastination}

Procrastination is defined as the postponement of a task, and a failure of self-regulation (Cao, 2012; Steel, 2007; Steel \& Klingsieck, 2016). Within the academic context, Sampaio and Bariani (2011), described procrastination as a phenomenon dependent on the individual's will and involving the behavior of systematically transferring, to another point in time, actions, attitudes, or relevant compromises, even considering the possibility of an unsatisfactory performance or a negative result, or both. It is a complex phenomenon, which generally cannot be attributed to a single cause. Procrastination is a prevalent behavior in students, and existing studies reported that $70-95 \%$ of university students claim to engage in procrastination (Sampaio \& Bariani, 2011; Steel, 2007). As such, procrastination may be considered an unsolved problem in society and among university students (Cavusoglu \& Karatas, 2015). Within the perspective of motivational and volitional psychology, procrastination is related to self-determination (Klingsieck, 2013), and 
it is useful to deal with procrastination as a self-determination deficit (Haghbin, McCaffrey, \& Pychyl, 2012).

Procrastination has a negative impact on academic results as well as implications on the students' health (Steel \& Klingsieck, 2016; Tice \& Baumeister, 1997; Tice \& Bratslavsky, 2000) and well-being (Balkis \& Duru, 2015; Steel \& Klingsieck, 2016). Procrastination is also associated to poor academic performance, poor planning skills (Rabin, Fogel, \& Nutter-Upham, 2011), increased stress (Beleaua \& Cocoradă, 2016; Lonka et al., 2014; Steel, 2007), and anxiety and depression (Ferrari, Johnson, \& McCown, 1995; Solomon \& Rothblum, 1984). There is a complex relation between procrastination and anxiety, which must be considered in a bi-directional context (Bolívar, Ballesteros, \& Ramírez, 2014).

\subsubsection{Coping Strategies}

There is an extensive range of investigations about stress and coping, analyzing the processes through which individuals anticipate or detect potential stress factors, and act to prevent them or to mitigate their consequences (Vaculíková, 2016). Schwarzer (2000) defined coping as an effort to deal with a stressful encounter that has already happened, and coping efforts are directed to either compensating for a loss or alleviating harm. More recently, the importance of the proactive coping strategy has been emphasized (Vaculíková \& Soukup, 2019). Proactive coping is perceived as a behavior or action that can be performed before the stressful situation appears (Vaculíková \& Soukup, 2019). Proactive coping is different from other types of coping because it anticipates any potential stressing situations, instead of reacting to stressful situations that already occurred (Greenglass \& Fiksenbaum, 2009). With proactive coping, people foresee risks, demands and opportunities, and are future-oriented as the individuals are able to take preparatory steps in coping with anticipated stress (Greenglass \& Fiksenbaum, 2009). In conclusion, individuals using a proactive coping strategy tend to have stronger personal growth with positive consequences in well-being and satisfaction with life (Greenglass, 2002).

\subsection{Basic Psychological Needs, Procrastination and Coping Strategies}

Regarding the relationship of procrastination with self-determination and with the satisfaction of the basic psychological needs, Senécal, Koestner, and Vallerand (1995) stated that self-determined students (i.e., acting according to their choices) had lower levels of procrastination than those not self-determined. Although self-determination and basic psychological needs have been associated to cognitive, affective and behavioral process (Deci \& Ryan, 1991, 1985), the specific 
relationship between basic psychological needs and procrastination has not been sufficiently studied. Procrastination has been negatively associated with the basic psychological needs satisfaction (Cavusoglu \& Karatas, 2015; Codina, Valenzuela, Pestana, \& Gonzalez-Conde, 2018).

SDT postulates that the basic psychological needs satisfaction leads to behavioral persistence and more positive psychological results (Deci \& Ryan, 2000; Sheldon, Ryan, Deci, \& Kasser, 2004). Haghbin et al. (2012) found that procrastination is linked to the non-satisfaction of the basic psychological needs of competence and autonomy. In the same vein, Deci and Ryan (2000) emphasized that competence is hardly enough to maintain a behavioral persistence, if autonomy is not also satisfied. This happens because autonomy is fundamental to understand the quality of a behavior (Ryan \& Deci, 2006).

Regarding the relationship between SDT and coping strategies, there are congruence points between proactive coping and SDT; proactive coping is based on individual activity, optimism and self-determination (Greenglass, Fiksenbaum, \& Eaton, 2006). In the same vein, SDT postulates that the human being is inherently proactive, directed to grow and to master both the inner and the environmental forces (Deci \& Ryan, 2000). In the academic context, basic psychological needs satisfaction was negatively related with avoidance strategies (Betoret \& Artiga, 2011), and autonomy and competence satisfaction positively predicted engagement coping (Shih, 2019).

There are positive relations of self-determination and basic psychological needs satisfaction with adaptive coping responses, as active coping, planning and search for instrumental support (Skinner, Edge, Altman, \& Sherwood, 2003), both in university students (Amiot, Blanchard, \& Gaudreau, 2008) and in athletes (Amiot, Gaudreau, \& Blanchard, 2004). Specifically, global self-determination predicted an increase in academic self-determination - a contextual-level motivation, through its impact on coping strategies (Amiot et al., 2008), and self-determined motivation negatively relates to less adaptive forms of coping, such as denial and non-involvement.

Finally, the research on the relation between procrastination and coping strategies has been mostly focused on the maladaptive coping strategies, the avoidance coping in particular (Sirois \& Kitner, 2015), and with much less focus on adaptive coping strategies. The combination of higher levels of maladaptative coping and lower levels of adaptive coping associated with procrastination indicates that procrastinators' preferred coping repertoire may confer risk for psychological well-being (Sirois \& Kitner, 2015). Current conceptualizations of procrastination link it to avoidant and disengagement coping, as a form of short-term mood regulation (Sirois \& Pychyl, 2013). In essence, avoiding unpleasant or stressful tasks as a mean of coping with the negative mood associated with these tasks is the modus operand of procrastinators (Sirois \& Kitner, 2015). Procrastination behaviors are considered to be relatively difficult to be modified because they provide a temporary comfort in a world full of demands, uncertainties and responsibilities, and are used as coping strategies to deal with aversive tasks (Basco, 2010). According to Seo (2013), the non-procrastinators tend to approach stressful situations using task-oriented coping strategies, while procrastinators tend to use emotion-oriented coping strategies and, more specifically, 
the avoidance strategy. Within an academic context, the daily study activity can be considered a stressor (Katz, Buzukashvili, \& Feingold, 2012) with students reporting that daily study involves conflicts and negative emotions (O'Rourke-Ferrara, 1998). Beleaua and Cocoradă (2016) found that participants who frequently procrastinate, engage more frequently in avoidance coping, and are less prone to use proactive coping and strategic planning, as these imply certain preparations in order to use them. Procrastination is negatively associated with task-oriented coping strategies, and positively associated with emotion-oriented and avoidance-oriented strategies (Flett, Blankstein, \& Martin, 1995; Sepehrian \& Lotf, 2011; Shih, 2019). A metaanalysis of 15 samples including over 4300 participants (Sirois \& Kitner, 2015) concluded that procrastination was negatively associated with adaptive coping and positively associated with maladaptive coping.

\subsubsection{Basic Psychological Needs, Coping and Procrastination in the Context of Healthy Aging}

Comparing three age groups, the younger one around 40-50, and the older one around 75, studies have found that the oldest group tend to present higher basic psychological needs fulfillment (Goulimaris, Mavridis, Genti, \& Rokka, 2014; Mackenzie, Karaoylas, \& Starzyk, 2017), higher well-being and lower stress (Goulimaris et al., 2014). Mackenzie et al. (2017) also found the basic psychological needs fulfillment mediates the relationship between motivational constructs and well-being outcomes in all age groups.

Regarding coping and age, in academic context, Sollár and Sollarova (2009) found that the oldest group (over 35 years) used more proactive coping, and also more reflective coping, strategic planning and preventive coping, compared with participants below 18 years and 18-34 years, while the younger groups have a higher preference for emotional support seeking strategies. In the same vein, Bagana, Negovan, and Vanea (2011) also found that younger university students had significantly lower proactive coping than the older ones, and showed a higher vulnerability to depression compared to the older students. Therefore, they seem to be poorly equipped for using proactive coping and, consequently, have a higher risk to develop depressive symptoms than older students. Whitty (2003) found that younger students (17-23 years) used more escape avoidance than older groups, of middle age and old age students.

Several studies have found that younger students procrastinate more than elder students, with procrastination declining across older age groups (Beutel et al., 2016; Rodríguez \& Clariana, 2017; Steel, 2007). In the same vein, Cao (2012) found that age was negatively related to procrastination in undergraduate students. It is seems that individuals procrastinate less as they age and learn (Steel, 2007), and have better control over themselves (Rodríguez \& Clariana, 2017). Finally, Beleaua and Cocoradă (2016) found that age negatively correlated with procrastination and stress, and positively correlated with proactive coping. 
Most of the research focused on procrastination in young students, and in the context of self-regulation. Therefore, it has not been approached in the context of healthy aging. The study of procrastination in a broad age range of adult students, with a focus on basic psychological needs and proactive coping, has not been explored. As we consider that the relations among these constructs may be relevant for healthy aging, this cross-sectional study has the purpose of assessing the relations among basic psychological needs satisfaction, procrastination and coping strategies in a broad age range of adult university students.

In the context of healthy aging, our main research question is whether procrastination, as a problematic behavior linked to lack of ability to face tasks and challenges in an adaptive way, may be reduced as students become more mature. We hypothesize that as age increases, the students will show lower procrastination, and more adaptive coping strategies. The role of basic needs satisfaction is approached in a more exploratory way.

\subsection{Method}

\subsubsection{Participants}

The convenience sample composed of 221 university students with ages between 18 and 69 years old $(M=25.56 ; S D=8.38)$, as in Portugal adulthood is legally attained at 18 years old (Carrilho, 2015). The students attained several courses; the majority were females $(57.5 \%)$ and singles $(86 \%)$.

\subsubsection{Instruments}

Basic Psychological Needs Scale. This self-report scale was originally developed by Gagné (2003), and has a Portuguese adaptation by Sousa, Ribeiro, Palmeira, Teixeira and Silva (2012). It has 21 items, distributed in three dimensions: Competence, Autonomy and Relatedness, with a total Basic Need Satisfaction Total score. It has a seven-point Likert response scale, ranging from 1 (not true) to 7 (completely true). In the current study, the internal consistency (alpha) coefficient of the total scale is 0.84 .

Proactive Coping Inventory. This self-report scale was developed by Greenglass, Schwarzer, Jakubiec, Fiksenbaum, and Taubert (1999), and the Portuguese version is by Marques, Lemos and Greenglass (2004). It has 55 items, distributed in seven dimensions: Proactive coping, Reflective coping, Strategic planning, Preventive coping, Instrumental support seeking, Emotional support seeking, and Avoidance coping. It has a four-point response scale, ranging from, 1 ("never") to 4 ("always"). In the current study, the internal consistency (alpha) coefficients for the 
subscale ranged from 0.68 and 0.84 , except for the subscale emotional support, which has an unacceptable value (alpha) coefficient 0.62 and has been removed from subsequent analysis.

Procrastination in Study Questionnaire. This self-report questionnaire was developed by Costa (2007) and has 10 items, distributed in two dimensions: "Procrastination in the daily study," and "Procrastination in studying for tests," with a total Procrastination score. It has a five-point Likert response scale, indicating the frequency of each procrastination behavior, from never (1) to always (5). The original validation study used a sample of basic education students and, in order to use this instrument with an university sample, there was an adaptation to the university level (Sampaio, 2011), which is similar to the original version, except for the vocabulary used in certain items were more appropriate to adult students. In the current study, the internal consistency (alpha) coefficient of the total scale is 0.81 .

Anxiety, Depression and Stress Scale-21. This self-report questionnaire was originally developed by Lovibond and Lovibond (1995), with a Portuguese adaption by Pais-Ribeiro, Honrado, and Leal (2004). It has 21 items, distributed in three dimensions designed to measure the emotional states of depression, anxiety and stress, and a total Anxiety, Depression and Stress score. It has a four-point response scale, indicating the severity and frequency of the perceived symptoms during the last seven days and ranging from "it didn't apply to me" (0) to "most of the times it applied to me" (3). In the current study, the internal consistency (alpha) coefficient of the total scale is 0.86 .

\subsubsection{Procedure}

Following the approval of the research project by the Ethical and Deontological Commission of the university, and the authorization granted by the directive board of each of the courses involved, the participants were recruited through a convenience sample method. The students were invited to participate in the study, following a formal explanation of the voluntary participation, and informed consent was obtained. Data was collected in person, through group applications in the classrooms. The whole process was in line with the ethical principles regarding investigations with human participants (American Psychological Association, 2010).

\subsubsection{Data Analysis}

Data were analyzed using Statistical Package for Social Sciences (SPSS) 24.0 and the statistical analysis were performed with a confidence level of $95 \%$. The internal consistency of the instruments was evaluated through the Cronbach's coefficient 
alpha. Pearson's correlation coefficients of the variables were calculated to assess the relations between them. Finally, a mediation analysis was performed, according to Hayes macro process (Hayes, 2013), to test if the proactive coping and the strategic planning coping strategies mediate the relation between basic psychological needs satisfaction and procrastination, using sociodemographic variables and the total score of anxiety, depression and stress as covariates.

\subsection{Results}

Correlations coefficients among the variables are presented in Table 11.1. Age has a positive correlation with only the basic psychological need for competence, but no significant correlation with autonomy, relatedness or total psychological needs. Regarding the coping strategies variables, it shows a positive correlation with proactive coping and strategic planning. Finally, age has a negative correlation with procrastination, and a total score of anxiety, depression and stress.

Total procrastination shows a negative correlation with basic psychological needs for autonomy and competence, and total psychological needs. It also shows a negative correlation with variables of coping strategies, proactive coping, reflective coping, strategic planning, and preventive coping, but a positive correlation with avoidance coping. Finally, it presents a positive correlation with a total score of anxiety, depression and stress.

Total basic psychological needs satisfaction has a positive correlation with proactive coping, strategic planning, preventive coping, and instrumental support seeking, but a negative correlation with avoidance coping. In the same vein, the three specific needs (competence, autonomy and relatedness) have a negative correlation with avoidance, whereas autonomy and competence have a positive correlation with proactive coping, strategic planning, and preventive coping. All the specific psychological needs, and the total score, have a negative correlation with total score of anxiety, depression and stress. Finally, proactive coping has a negative correlation with the total score of anxiety, depression and stress. On the contrary, avoidance coping has a positive correlation with anxiety, depression and stress.

In Fig. 11.1, we may see the mediation model (Hayes, 2013), intending to verify if the satisfaction of the basic psychological needs is a predictor of total procrastination, in a relation mediated by the proactive coping strategy and by the strategic planning coping strategy. The regression of the satisfaction of the basic psychological needs over procrastination, ignoring the mediators, was significant: $(\beta=-0.85, t(215)=-4.54, p=0.000)$. The regression of the basic psychological needs satisfaction over the mediators proactive coping $(\beta=1.08, t(215)=7.23, p$ $=0.0000)$ and strategic planning $(\beta=0.24, t(215)=3.18, p=0.000)$, was equally significant. Controlling the basic psychological needs satisfaction, both mediators, proactive coping $(\beta=-0.28, t(213)=-3.42, p=0.000)$ and strategic planning $(\beta$ $=-0.56 t(213)=-3.44, p=0.000)$, revealed a significant effect over total procrastination. Controlling the mediator variables proactive coping and strategic 


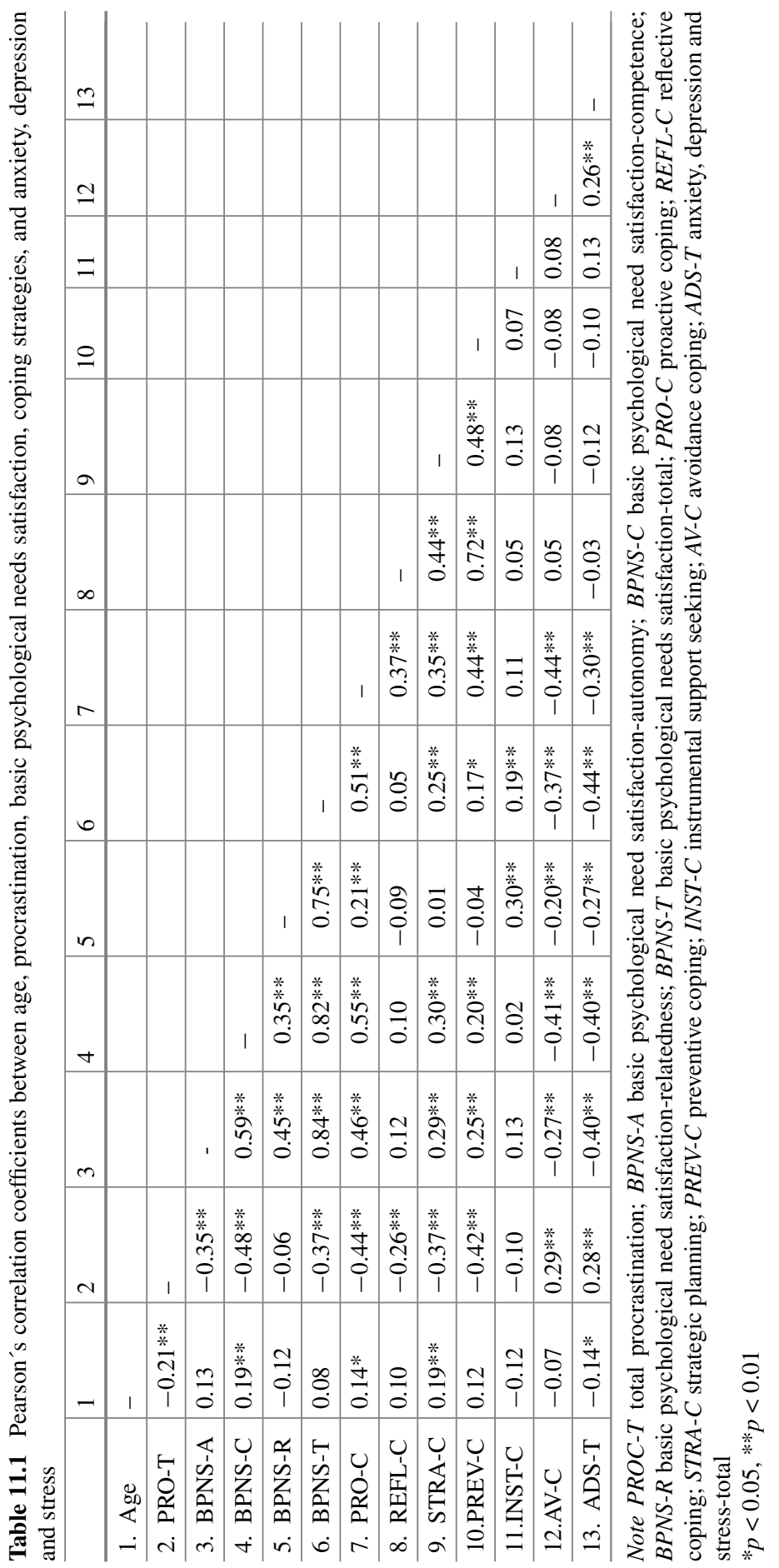




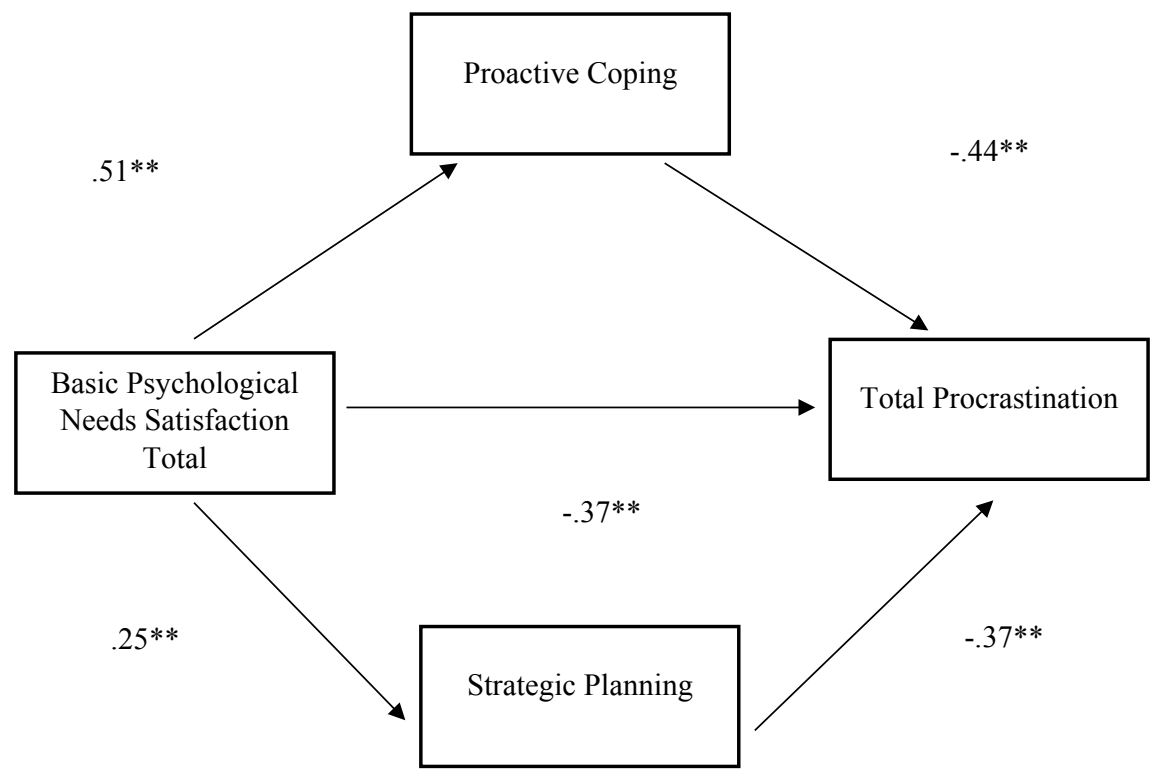

Fig. 11.1 Standardized regression coefficients for the relationship between basic psychological needs satisfaction total and total procrastination, mediated by the proactive coping and strategic planning. $* * p<0.001 ; * p<0.01$

planning, the satisfaction of the basic psychological needs continues to be a significant predictor of total procrastination: $(\beta=-0.41, t(213)=-2.08, p=$ 0.039 . The Sobel's test found partial mediation in the model for proactive coping ( $\mathrm{z}$ $=-0.3 .06, p=0.002)$ and for strategic planning $(\mathrm{z}=-0.2 .28, p=0.022)$. Therefore, the satisfaction of the basic psychological needs is a predictor of the total procrastination, in a relation partly mediated by the proactive coping and by the strategic planning coping strategies.

\subsection{Discussion}

This research intended to examine the relations between procrastination, basic psychological needs, coping strategies, and anxiety, depression and stress, in the context of healthy aging. The relations among procrastination, basic psychological needs and coping strategies will be discussed firstly with a subsequent focus on the role of age. There was a positive relation between procrastination and anxiety, depression and stress. Within the academic context, procrastination is related with anxiety, depression and stress, and it is a trigger of ill-being. Identical results were found in other studies (Ferrari et al., 1995; Rabin et al., 2011; Solomon \& Rothblum, 1984; Steel, 2007; Verešová, 2013). 
The total satisfaction of the basic psychological needs, and the specific needs of competence and autonomy, negatively correlated with procrastination. Only relatedness did not correlate with procrastination. Overall, the results are congruent with the literature (Cavusoglu \& Karatas, 2015; Codina et al., 2018). Competence is a predictor of lower procrastination, as it provides students with a sense of efficacy at overcoming obstacles that keeps them optimistic facing challenges, and confident in their abilities to accomplish unpleasant tasks (Shih, 2019). When learners are autonomous, they will spend their energy studying, and when they are competent, they will make efforts to cope with difficulties in academic work (Niemiec \& Ryan, 2009). Concerning relatedness, Shih (2019) has also found that relatedness is the psychological need with lower correlation with procrastination. Relatedness has been considered less central in the individual's determination and less influent on intrinsic motivation, when compared to the needs of competence and autonomy, since people often engage in intrinsically motivated behavior in isolation (Deci \& Ryan, 2000; Shih, 2019). It is apparent that relatedness has been the basic psychological need with less consistent results, with some studies finding no significant correlation between relatedness and variables such as subjective well-being, anxiety, or life satisfaction (Tang, Wang, \& Guerrien, 2019).

We found a positive relation between basic psychological needs satisfaction and proactive coping, strategic planning, preventive coping, and instrumental support seeking. The psychological needs have a negative relation with avoidance coping. Similar findings were shown by Bakracheva (2019), with students and non-student participants. Similar relations with adaptive strategies were also found in the academic context (Amiot et al., 2008; Shih, 2019). SDT looks at the individual as being an active and integrative organism directed toward an objective, requiring certain nutrients/supports to function in an optimal way (Deci \& Ryan, 2002). Proactive coping, being based on individual initiative, optimism and self-determination (Greenglass et al., 2006), is consistent with self-determined behavior and inconsistent with procrastination behavior. In our mediation model, proactive coping and strategic planning were both partial mediators of the relation between the satisfaction of the basic psychological needs and procrastination. With some conceptual similarity, proactive coping totally mediated the relation between self-blame and stress in university students (Straud \& McNaughton-Cassil, 2019), and between stress and the engagement with study (Gan, Yang, Zhou, \& Zhang, 2007). These studies showed that lower stress was a predictor of a better use of proactive coping, leading to a higher engagement in studying. Although we are not aware of any study with strategic planning as a mediator between the basic psychological needs and procrastination, our result is consistent with studies that show the negative relation of strategic planning with procrastination (Beleaua \& Cocoradă, 2016). Future studies should test this variable in their models.

With a focus on age, we are not aware of any study focused on the relation between age and basic psychological needs, within the university context. The results of our study show a positive relation between age and competence, which corroborates the perception that aging provides the individuals with a higher sense of efficiency in performing the actions required to achieve academic outcomes. According to Deci 
and Ryan (2002), competence is not an attained skill or capability, but rather is a felt sense of confidence and effectiveness in action. We did not find a significant relation of age with autonomy or relatedness, and we interpret it in the context of our sample. For university students, competence is central in the everyday academic tasks, more relevant than self-initiative and self-regulation of their own actions. In the same vein, developing secure and satisfying connections with others, in the university environment, may not be as relevant as in other contexts.

Age had a positive correlation with proactive coping and with strategic planning, which is similar to the results of several studies, both with students (Bagana et al., 2011; Vaculíková, 2016) and non-students (Sollár \& Sollarova, 2009). Age had a negative relation with procrastination, which is similar to several results (Beleaua \& Cocoradă, 2016; Cao, 2012; Rodríguez \& Clariana, 2017; Steel 2007). It seems congruent with the suggestion of Cao (2012) that possibly students may tend to procrastinate progressively less as they become more experienced in school and more mature in life. Finally, age had a negative relation with anxiety, depression and stress. We interpret it in terms of the lower procrastination, and, especially, the higher psychological needs satisfaction the older students have shown, as these basic needs have proven to contribute to well-being in a comparable degree in young, middle aged and older adults (Mackenzie et al., 2017).

The results of this study must be interpreted taking in consideration some methodological limitations. Being a cross-sectional analysis, it prevents the identification of a direct causality between the variables. Due to the use of self-report instruments, social desirability may be considered.

\subsection{Implications and Conclusion}

We find two main implications of our results, closely interrelated: satisfaction of the basic psychological needs contributes to a more motivated learning and active involvement, through adaptive coping strategies, and, as students grow older, more satisfaction and less procrastination seem to occur. In the same vein, the continuous involvement in academic activities must be encouraged as a way to reinforce these psychological needs satisfaction in the context of healthy aging. This requires an academic context that stimulates the needs satisfaction, and consequently favors well-being.

In sum, from the SDT perspective, our results show that, when the basic psychological needs of the students are more satisfied, they will have a higher tendency to use proactive coping, and through this proactive coping, they will have lower procrastination behaviors. If the individual feels autonomous and competent in the performed activities, he or she will be more self-conscious and have higher perception of choices (Deci \& Ryan, 2000). The satisfaction of basic psychological needs will enable students to deal with the stressors inherent to the academic activities in a much more adaptive way (Gan, Hu, \& Zhang, 2010). They will have 
more initiative, looking for challenges and perceiving academic activities and evaluations not as stressors, but as goals to achieve.

SDT assumes that all people, independently of age and culture, have an active tendency to growth and to psychological integration (Deci \& Ryan, 2000) and an innate tendency to satisfy their basic needs of competence, autonomy and relatedness across their lives. The three basic needs specify innate psychological nutrients, essential for a continuous psychological growth, integrity and well-being, throughout life. Therefore, they are essential in every life phase to pursue life goals, even if those goals may vary over time.

According to SDT, the innate basic psychological needs are the basis of human motivation toward an integrated development of the self, which takes place within the social structures (Deci \& Ryan, 2000). As such, it is necessary that the environment provides the strengthening of those three basic psychological needs for the student to feel more involved with the learning tasks, even when those tasks are originally evaluated as difficult.

Being involved in academic activities may be a way for adults and older people to improve their basic psychological needs and, as the older students tend to internalize the activities in which they are interested, the academic context should consider these needs satisfaction in order to promote higher levels of psychological well-being. Only when an activity satisfies the personal need for competence, autonomy and relatedness, the activity will be lived as pleasant and the involvement in it will occur for internal reasons (Goulimaris et al., 2014). As age increases, we tend to be more involved in activities as they are able to intrinsically motivate us, and that is why a context that satisfies the psychological needs seems even more relevant for older students. In this context, proactive coping strategies, directed to an increase of personal resources that may reduce the occurrence of stress factors, and at the same time facilitate the goals achievement (Schwarzer, 2000), should be trained with students of all ages as a tool to achieve healthy aging. The psychological needs satisfaction encourages the use of a deeper learning approach, and subsequently decreases the students' avoidance strategies. While students who perceived their basic psychological needs being less satisfied, they tended to adopt a surface learning approach (Betoret \& Artiga, 2011). Betoret and Artiga (2011) stated that some instructional aspects under teacher control (as teaching methodology, task proposed, classroom layout, and interaction with students) may be very relevant in the fulfillment of the students' psychological needs. A need-supportive teaching has been proven very relevant to increase the motivation of students with special educational needs, as considering the student preferences, interests and opportunities to make choices contribute to self-determination by motivating participation, autonomy and learning (Haakma, Janssen, \& Minnaert, 2017). We think that the use of need-supportive strategies should be increasingly used with adult students, of different age groups, simultaneously contributing to well-being and to academic achievement in the scope of healthy aging. 


\section{References}

American Psychological Association. (2010). Publication manual of the American Psychological Association (6th ed.). Washington, DC: Author Edition.

Amiot, C. E., Gaudreau, P., \& Blanchard, C. M. (2004). Self-determination, coping, and goal attainment in sport. Journal of Sport and Exercise Psychology, 26, 396-411.

Amiot, E. C., Blanchard, M. C., \& Gaudreau, P. (2008). The self in change: A longitudinal investigation of coping and self-determination process. Self and Identity, 7, 204-224. https:// doi.org/10.1080/15298860701580793

Bagana, E., Negovan, V., \& Vanea, M. (2011). Proactive coping and vulnerability to depression in university environment-gender, age and learning context differences. Procedia-Social and Behavioral Science, 12, 30-39. https://doi.org/10.1016/j.sbspro.2011.02.007

Bakracheva, M. (2019). Coping effects on life meaning, basic psychological needs and well-being. Psychology, 10, 1375-1395. https://doi.org/10.4236/psych.2019.1010090

Balkis, M., \& Duru, E. (2015). Procrastination, self-regulation failure, academic life satisfaction, and effective well-being: Underregulation or misregulation form. European Journal of Psychology of Education. https://doi.org/10.1007/s10212-015-0266-5

Basco, M. R. (2010). The procrastinator's guide to getting thing done. New York: Guilford.

Beleaua, R., \& Cocoradă, E. (2016). Procrastination, stress and coping in students and employees. Romanian Journal of Experimental Applied Psychology, 7(1). https://doi.org/10.15303/rjeap. 2016.si1.a40.

Betoret, F. D., \& Artiga, A. G. (2011). The relationship among student basic need satisfaction, approaches to learning, reporting of avoidance strategies and achievement. Electronic Journal of Research in Educational Psychology, 9, 463-496.

Beutel, M. E., Klein, E. M., Aufenanger, S., Brähler, E., Dreier, M., Müller, K. W. ... Wölfling, K. (2016). Procrastination, distress and life satisfaction across the age range-A German representative community study. PLOS ONE, 11, e0148054. https://doi.org/10.1371/journal.pone. 0148054.

Bolívar, D., Ballesteros, L., \& Ramírez, C. (2014). Relación entre procrastination académica y ansiedad-rasgo en estudiantes de psicologia [Relationship between academic procrastination and trait anxiety in psychology students]. Cuadernos Hispanoamericanos de Psicologia, 14, 31-44.

Cao, L. (2012). Differences in procrastination and motivation between undergraduate and graduate students. Journal of the Scholarship of Teaching and Learning, 12, 39-64.

Carrilho, M. J. (2015). Crianças e adolescentes em Portugal [Children and adolescents in Portugal]. Revista de Estudos Demográficos, 55, 53-101.

Cavusoglu, C., \& Karatas, H. (2015). Academic procrastination of undergraduate: Selfdetermination theory and academic motivation. Antropologist, 20, 735-743.

Codina, N., Valenzuela, R., Pestana, J. V., \& Gonzalez-Conde, J. (2018). Relationship between student procrastination and teaching styles: Autonomy-supportive and controlling. Frontiers in Psychology. https://doi.org/10.3389/fpsyg.2018.00809

Costa, M. (2007). Procrastinação, autorregulação e género [Procrastination, self-regulation and gender]. (Unpublished master's thesis). Minho University, Braga, Portugal.

Deci, E. L., \& Ryan, R. M. (1985). Intrinsic motivation and self-determination in human behavior. New York: Plenum.

Deci, E. L., \& Ryan, R. M. (1991). A motivational approach to self: Integration in personality. In R. A. Dienstibier (Ed.), Current theory and research in motivation, vol. 38. Nebraska Symposion on Motivation, 1990: Perspectives on motivation (pp. 237-288) Lincoln, NE: University of Nebraska Press.

Deci, E. L., \& Ryan, R. M. (2000). The "what" and "why" of goal pursuits: Human needs and the self-determination of behavior. Psychological Inquiry, 11, 227-268.

Deci, E. L., \& Ryan, R. M. (2002). Handbook of self-determination research. Rochester, NY: University of Rochester Press. 
Deci, E. L., Vallerand, R. J., Pelletier, L. G., \& Ryan, R. M. (2011). Motivation and Education: The self-determination perspective. Educational Psychologist, 26, 325-346. https://doi.org/10.1080/ 00461520.1991 .9653137

Dziechciaz, M., \& Filip, R. (2014). Biological psychological and social determinants of old age: Bio-psyco-social aspects of human aging. Annals Agricultural and Environmental Medicine, 21, 835-838. https://doi.org/10.5604/12321966.1129943

Fernandez-Ballesteros, R. (2013). Possibilities and limitation of age. In A. L. Oliveira (Coord.), Promoting conscious and active learning aging. How to face current and future challenges? (pp. 25-70). Coimbra: Coimbra University Press.

Ferrari, J. R., Johnson, J., \& McCown, W. (1995). Procrastination and task avoidance: Theory, research and practice. New York, NY: Plenum Press.

Flett, G. L., Blankstein, K. R., \& Martin, T. R. (1995). Procrastination, negative self-evaluation, and stress in depression and anxiety: A review and preliminary model. In J. R. Ferrari, J. L. Johnson, \& W. G. McCown (Eds.), Procrastination and task avoidance: Theory, research, and treatment (pp. 137-167). New York, NY: Plenum Press.

Gagné, M. (2003). The role of autonomy support and autonomy orientation in prosocial behavior engagement. Motivation and Emotion, 27, 199-223.

Gan, Y., Hu, Y., \& Zhang, Y. (2010). Proactive and preventive coping in adjustment to college. The Psychological Record, 60, 643-658.

Gan, Y., Yang, M., Zhou, Y., \& Zhang, Y. (2007). The two factor structure of future-oriented coping and its mediating role in student engagement. Personality and Individual Differences, 43, 851-863. https://doi.org/10.1016/j.paid.2007.02.009

Goulimaris, D., Mavridis, G., Genti, M., \& Rokka, S. (2014). Relationship between basic psychological needs and psychological well-being in recreation dance activities. Journal of Physical Education and Sport, 14, 227-284. https://doi.org/10.7752/jpes.2014.02042

Greenglass, E. R. (2002). Proactive coping. In E. Frydenberg (Ed.), Beyond coping: Meeting goals, vision and challenges (pp. 37-62). London: Oxford University Press.

Greenglass, E. R., \& Fiksenbaum, L. (2009). Proactive coping, positive affect, and well-being: Testing for mediation using path analysis. European Psychologist. https://doi.org/10.1027/10169040.14.1.29

Greenglass, E. R., Fiksenbaum, L., \& Eaton, J. (2006). The relationship between coping, social support, functional disability and depression in the elderly. Anxiety, Stress, and Coping, 19, 15-31. https://doi.org/10.1080/14659890500436430

Greenglass, E., Schwarzer, R., Jakubiec, D., Fiksenbaum, L., \& Taubert, S. (1999). The proactive coping inventory (PCI): A Multidimensional Research Instrument. Paper presented at the 20th International Conference of the Stress and Anxiety Research Society (Stars), Cracow, Poland, July 12-14, 1999.

Haakma, I., Janssen, M., \& Minnaert, A. (2017). Intervening to improve teachers' need-supportive behaviour using self-determination theory: Its effects on teachers and on the motivation of students with deafblindness. International Journal of Disability, Development \& Education, 64, 310-327.

Haghbin, M., McCaffrey, A., \& Pychyl, T. A. (2012). The complexity of the relationship between fear of failure and procrastination. Journal of Relational-Emotive and Cognitive-Behaviour Therapy, 30, 249-263. https://doi.org/10.1007/s10942-012-0153-9

Hayes, A. F. (2013). Introduction to mediation, moderation, and conditional process analysis: A regression-based approach. New York, NY: Guilford.

Katz, I., Buzukashvili, T., \& Feingold, L. (2012). Homework stress: Construct validation of a measure. The Journal of Experimental Education, 80, 405-421. https://doi.org/10.1080/002 20973.2011.610389

Klingsieck, K. B. (2013). Procrastination: When good thinks don't come to those who wait. European Psychologist, 18, 24-34. https://doi.org/10.1027/1016-9040/a000138

Lonka, K., Chow, A., Keskinen, J., Hakkarainen, K., Sandström, N., \& Pyhältö, K. (2014). How to measure Ph.D. Students' conceptions of academic writing, and are they related well-being? Journal of Writing Research, 5, 245-269. https://doi.org/10.17239/jowr-2014.05.03.01 
Lovibond, P., \& Lovibond, S. (1995). The structure of negative emotional states: Comparison of the depression anxiety stress scales (DASS) with the Beck Depression and Anxiety Inventories. Behaviour Research and Therapy, 33(3), 335-343.

Mackenzie, C. S., Karaoylas, E. C., \& Starzyk, K. B. (2017). Lifespan differences in a selfdetermination theory model of eudaimonia: A cross-sectional survey of younger, middle-aged, and older adults. Journal of Happiness Studies, 18, 1-23.

Marques, S., Lemos, J., \& Greenglass, R. (2004). Proactive coping inventor (PCI), Portuguese Version. Accessed from https://www.psych.yorku.ca/greenglass/.

Niemiec, C., \& Ryan, R. M. (2009). Autonomy, competence, and relatedness in the classroom. Applying self-determination theory to educational practice. Theory and Research in Education, 7, 133-144. https://doi.org/10.1177/1477878509104318

Ntoumanis, N., Edmunds, J., \& Duda, J. L. (2009). Understanding the coping process from a selfdetermination theory perspective. British Journal of Health Psychology, 14, 249-260. https://doi. org/10.1348/135910708x349352

O'Rourke-Ferrara, C. (1998). Did you complete all your homework tonight dear? New York: Elementary and Early Childhood Education Clearinghouse.

Pais-Ribeiro, L. J., Honrado, A., \& Leal, I. (2004). Contribuição para o estudo da adaptação das escalas de ansiedade, depressão e stresse (EADS) de 21 itens de Lovibond e Lovibond [Contribution for the study of the adaptation of the anxiety, depression and stress scales (DASS) of 21 items of Lovibond and Lovibond]. Psicologia, Saúde \& Doenças, 5, 229-239.

Rabin, L., Fogel, J., \& Nutter-Upham, K. (2011). Academic procrastination in college students: The role of self-reported executive function. Journal of Clinical and Experimental Neuropsychology, 33, 344-357. https://doi.org/10.1080/13803395.2010.518597

Rodríguez, A., \& Clariana, M. (2017). Procrastinación en estudiantes universitários: Su relación con la edade y el curso académico [Procrastination in university students: Relationship with age and academic course]. Revista Colombiana de Psicologia, 26, 45-60. https://doi.org/10.15446/ rcp.v26n1.53572

Ryan, R. M., \& Deci, E. L. (2000). Self-determination theory and the facilitation of intrinsic motivation, social development and well-being. American Psychologist, 55, 68-78.

Ryan, R. M., \& Deci, E. L. (2006). Self-regulation and the problem of human autonomy: Does psychology need choice, self-determination and will? Journal of Personality, 74. https://doi.org/ 10.1111/j.1467-6494.2006.00420.x.

Ryan, R. M., \& La Guardia, J. G. (2000). What is being optimized? Self-determination theory and basic psychological needs. In S. H. Qualls \& N. Abeles (Eds.), Psychology and the aging revolution: How we adapt to longer life (pp. 145-172). Washington, DC: American Psychological Association. https://doi.org/10.1037/10363-008.

Sampaio, R. K. N. (2011). Procrastinação académica e autorregulação da aprendizagem em estudantes universitários [Academic procrastination and self-regulation for learning in university students]. (Unpublished master's thesis). State University of Campinas, Campinas, Brasil.

Sampaio, R. K. N., \& Bariani, I. C. D. (2011). Procrastinação acadêmica: Um estudo exploratório [Academic procrastination: An exploratory study]. Estudos Interdisciplinares em Psicologia, 2, 242-262. https://doi.org/10.5433/2236-6407.2011v2n2p242

Schwarzer, R. (2000). Manage stress at work through preventive and proactive coping. In E. A. Locke (Coord.), The blackwell handbook of principles of organization behaviour (Vol. 24, pp. 342-355). Oxford: Blackwell.

Senécal, C., Koestner, R., \& Vallerand, R. (1995). Self-Regulation and academic procrastination. The Journal of Social Psychology, 135, 607-619.

Seo, E. H. (2013). A comparison of active and passive procrastination in relation to academic motivation. Social Behavior and Personality, 41, 777-786. https://doi.org/10.2224/sbp.2013.41. 5.777

Sepehrian, F., \& Lotf, J. (2011). The effects of coping styles and gender on academic procrastination among university students. Journal of Basic and Applied Scientific Research, 1, 2987-2993. 
Sheldon, K. M., Ryan, R. M., Deci, E. L., \& Kasser, T. (2004). The independent effects of goal contents and motives on well-being: It's both what you purpose and why you purpose it. Personality and Social Psychology Bulletin, 30, 475-486. https://doi.org/10.1177/014616720 3261883

Shih, S. (2019). An examination of academic coping and procrastination from the self-determination theory perspective. Journal of Education and Human Development, 8, 57-68. https://doi.org/10. 15640/jehd.v8n1a8

Sirois, F. M., \& Kitner, R. (2015). Less adaptive or more maladaptive? A meta-analytic investigation of procrastination and coping. European Journal of Personality, 29, 433-444. https://doi.org/10. 1002/per.1985

Sirois, F. M., \& Pychyl, T. (2013). Procrastination and the priority of short-term mood regulation: Consequences for future self. Social and Personality Psychology Compass, 7, 115-127.

Skinner, E. A., Edge, K., Altman, J., \& Sherwood, H. (2003). Searching for the structure of coping: A review and critique of category systems for classifying ways of coping. Psychological Bulletin, 19, 216-269. https://doi.org/10.1037/0033-2909.129.2.216

Sollár, T., \& Sollarova, E. (2009). Proactive coping from the perspective of age, gender, and education. Studia Psychologica, 51, 161-165.

Solomon, L. J., \& Rothblum, E. D. (1984). Academic procrastination: Frequency and cognitivebehavioral correlates. Journal of Counseling Psychology, 31, 503-509.

Sousa, S. S., Ribeiro, J. L. P., Palmeira, A. L., Teixeira, P. J., \& Silva, M. N. (2012). Estudo da basic need satisfaction in general scale para a língua portuguesa [Study of basic need satisfaction in general scale for portuguese language]. Psicologia, Saúde e Doenças, 13, 209-219.

Steel, P. (2007). The nature of procrastination: A meta-analytic and theoretical review of quintessential self-regulatory failure. Psychological Bulletin, 133, 65-94. https://doi.org/10.1037/ 0033-2909.133.1.65

Steel, P., \& Klingsieck, K. (2016). Academic procrastination: Antecedents revisited. Australian Psychological Society, 5, 36-46. https://doi.org/10.1111/ap.12173.

Straud, C., \& McNaughton-Cassil, M. (2019). Self-blame and stress in undergraduate college students: The mediating role of proactive coping. Journal of American College Health, 67, 367-373. https://doi.org/10.1080/07448481.2018.1484360

Tang, M., Wang, D., \& Guerrien, A. (2019). A systematic review and meta-analysis on basic psychological need satisfaction, motivation, and well-being in later life: Contributions of selfdetermination theory. Psychology Journal. https://doi.org/10.1002/pchj.293

Tice, D. M., \& Baumeister, R. F. (1997). Longitudinal study of procrastination, performance, stress, and health: The costs and benefits of dawdling. Psychological Science, 8, 454-458. https://doi. org/10.1111/j.1467-9280

Tice, D. M., \& Bratslavsky, E. (2000). Giving in to feel good: The place of emotion regulation in the context of general self-control. Psychological Inquiry, 11, 149-159.

Vaculíková, J. (2016). Proactive coping behavior in sample of university students in helping profession. Social Education, 4, 38-55. https://doi.org/10.7441/soced.2016.04.03

Vaculíková, J., \& Soukup, P. (2019). Mediation pattern of proactive coping and social support on well-being and depression. International Journal of Psychology \& Psychological Therapy, 19(1), 39-54.

Verešová, M. (2013). Procrastination, stress and coping among primary school teacher. ProcediaSocial and Behavioral Science. https://doi.org/10.1016/j.sbspro.2013.12.243

Whitty, M. T. (2003). Coping and defending: Age differences in maturity of defense mechanisms and coping strategies. Aging and Mental Health, 7, 123-132. https://doi.org/10.1080/136078603 1000072277

World Health Organization. (2015). Draft 1: Global strategy and action plain on aging and health. Retrieved from https://www.who.int/aging/aging-global-strategy-draft1-en.pdf. 